\title{
Determination of Species Concentrations of Ti-6Al-4V Titanium Alloys using Calibration Free Laser Induced Breakdown Spectroscopy
}

\author{
Tagreed K. Hamad and Hussein T. Salloom
}

\begin{abstract}
In this study, Calibration-free Laser-induced breakdown spectroscopy (CF-LIBS) was applied to quantitatively analyze the elemental composition of Ti-6Al-4V titanium based alloy samples with no need for matrix-matched calibration procedure. Nd: YAG pulsed laser operating at a wavelength of $1064 \mathrm{~nm}$ was focused onto the sample to generate plasma. The spectrum of plasma was recorded using spectrophotometer then compared to NIST spectral lines to determine characteristic wavelengths, energy levels and other spectroscopic parameters. The values of plasma temperature obtained using Boltzmann plot for four examined samples ranged from 7439 to $6826 \mathrm{~K}$ while the electron density for each element was determined using Boltzmann-Saha equation. The concentration of $\mathrm{Ti}, \mathrm{Al}, \mathrm{V}$ and $\mathrm{Fe}$ has been determined and were within the samples nominal concentrations obtained from XRF analysis. The calculated average relative errors of $\mathbf{T i}, \mathbf{A l}$, $\mathrm{V}$ and $\mathrm{Fe}$ were $0.39 \%, 4.38 \%, 4.94 \%$ and $8.2 \%$, respectively. Finally, there was a direct proportionality relation between the ratio of ionic to neutral emission lines of $\mathrm{Ti}$ for four samples and the surface hardness values measured mechanically using Vickers hardness test. The ratio at (Ti II $252.56 \mathrm{~nm}$ )/(Ti I $294.82 \mathrm{~nm})$ had the best linear regression value $\left(R^{2}=0.95\right)$ which indicates the best correlation with surface hardness.
\end{abstract}

Index Terms-CF-LIBS Technique; Hardness; Plasma Temperature; Quantitative Analysis.

\section{INTRODUCTION}

Ti-6Al-4V is one of the most important titanium alloys owing to appealing properties including biomedical compatibility, excellent strength-to-weight ratio high corrosion and mechanical resistance [1], [2]. With these factors in mind, Ti-6Al-4V has found applications in a variety of fields such as medical and dental implant, aerospace automobile, subsea oil, petrochemical and many more industries [3]. The nominal composition of Ti-6Al-4V alloy is $6 \%$ of $\mathrm{Al}, 4 \%$ of $\mathrm{V}$ and $\mathrm{Ti}$, its chemical and mechanical properties will be affected by any small variation in these concentrations, leading to probable mechanical failure.

Among many available composition analysis instruments, laser induced breakdown spectroscopy (LIBS) would be preferable for hard material due to its superior advantages such as the possibility to direct analysis, requiring little or

Published on August 31, 2018.

T. K. Hamad is with the Department of Physics, College of Sciences AlNahrain University, Baghdad, Iraq (e-mail: Tagreed_k@yahoo.com)

H. T. Salloom is with Al-Nahrain Nanorenewable energy research center, Al- Nahrain University, Baghdad, Iraq who participated in part of this work. (e-mail:abnthamer@gmail.com,

dr.husseinthamer@nerc.nahrainuniv.edu.iq). no sample preparation and the simplicity of experimental set up [4], [5]. Furthermore, LIBS based quantitative analysis can be carried out using either calibration curves built from certified reference matrix matched samples or calibration free procedure which depends on spectral data and plasma parameters analysis with no need for references samples. Since the first proposed by Ciccui et al. [6] in 1999 and in the following years, calibration- free CF-LIBS technique was applied as a fast and accurate method for the precise determination of elements in metallic and non-metallic alloys [7], [8], ceramic materials [9], soil samples [10] and many others.

On the other hand, scientific literatures revealed that LIBS analysis can not only use for the elemental composition of the solids, but it can be used for determining their surface hardness. Tsuyuki et al. [11] investigated the potential of LIBS to determine compressive strength of concrete. In this study, the emission intensity ratio between $\mathrm{Ca}(\mathrm{II})$ at $396.8 \mathrm{~nm}$ and $\mathrm{Ca}(\mathrm{I})$ at $422.6 \mathrm{~nm}$ in Nd:YAG LaserInduced Plasma can be used to examine the hardness of the material. In related study, Abdel-Salam et al [12] were able to examine the surface hardness of human tooth by monitoring the ratio of $\mathrm{CaII} / \mathrm{CaI}$ and $\mathrm{MgII} / \mathrm{MgI}$, they observed that these ratios changed with respect to the change in the surface hardness.

The goal of this study was to investigate the analytical capability of CF-LIBS, to obtain the accurate elemental composition of four different Ti alloys. The LIBS results are confirmed by XRF technique. Another goal of this study was to correlate intensities acquired by laser technique with mechanical micro hardness values, which were obtained by Vickers test.

\section{EXPERIMENTAL SETUP}

The laser induced plasma was produced by ablating a Ti$6 \mathrm{Al}-4 \mathrm{~V}$ alloy target with the laser pulses from Nd: YAG laser operating at wavelength of $1064 \mathrm{~nm}$ with energy of 150 $\mathrm{mJ}$ and pulse width of $9 \mathrm{~ns}$. The spot size at the focus was approximately $0.03 \mathrm{~cm}$, accordingly laser intensity was $5.95 * 10^{9} \mathrm{~W} / \mathrm{cm}^{2}$. The surface target was fixed perpendicular to the laser beam on a motorized stage for fresh positioning to each laser shot. The plasma emission was collected using a multi-mode optical fiber cable of $400 \mu \mathrm{m}$ diameter located at $45^{\circ}$ angle with the normal at $10 \mathrm{~cm}$ distance from the focused spot. The collected plasma emission was translated through the optical fiber to the entrance slit of an optical spectrometer specified for spectral wavelength range of (200-1100) nm equipped with CCD camera. The data analysis and the spectral lines identification were achieved 
by NIST atomic spectral database. Each of the LIBS emission spectra represents the average of 10 spectra at different positions on target. For comparison purposes, XRF fluorescence spectrometer of type multi-channel MXF 2400 from Shimadzu was used for elemental analysis of examined samples.

\section{RESULTS AND DISCUSSION}

\section{A. Ti alloy ablation by laser}

In order to produce stoichiometric ablation and the plasma provide the identification of the all species present in the Ti- target, the laser power density and corresponding ablation mechanical pressure should be enough to induce ionization and exceed a material specific threshold value. First, the ablation pressure $\mathrm{Pa}$ was estimated according to experimental parameters, using the following formula:

$$
P a=C m * I
$$

Where $\mathrm{Cm}$ is mechanical coupling coefficient, I is the laser intensity. $\mathrm{Cm}$ was calculated using an empirical formula concluded by Phipps et al [13] as given:

$$
C m=b\left(I \cdot \lambda \cdot \tau^{1 / 2}\right)^{n}
$$

$\mathrm{b}$ and $\mathrm{n}$ are material-dependent parameter equal to 5.5 and -0.3 respectively, $\lambda$ is the laser wavelength of $1064 \mathrm{~nm}, \tau$ is the pulse width $9 \mathrm{~ns}$. Accordingly, the ablation pressure was equal to $(2.14 \mathrm{kbar})$ for $\mathrm{I}=5.95 * 10^{9} \mathrm{~W} / \mathrm{cm}^{2}$, this pressure was enough to remove the ablated mass.

\section{B. Plasma Emission spectra}

LIBS spectra of Ti alloy in the spectral range 230-330, 400-650 and 700-950 $\mathrm{nm}$ are shown in Fig. 1a, b and c respectively. The emission lines with minimal interference and maximum signal intensity were selected. The NIST atomic spectral database [14] was used to identify all the recorded spectral lines. The majority of emission lines observed in this figure belong to neutral and first ionization state of Titanium (Ti), Aluminum (Al) Vanadium (V) and Iron $(\mathrm{Fe})$ as the alloy basically contains these elements. These emission lines, along with their spectroscopic parameters are given in Table. I.

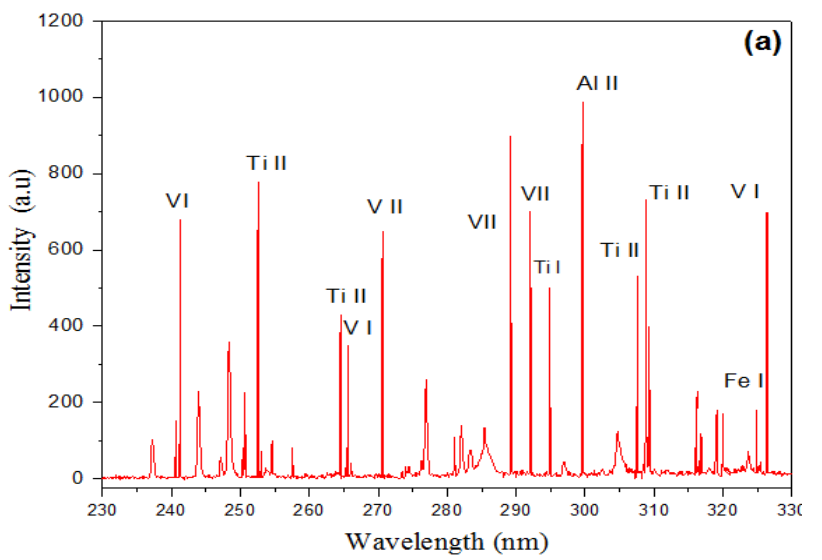

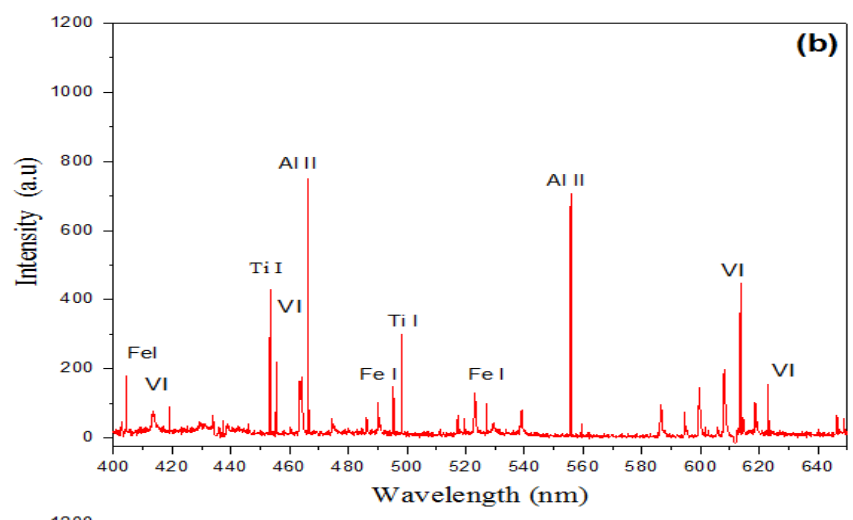

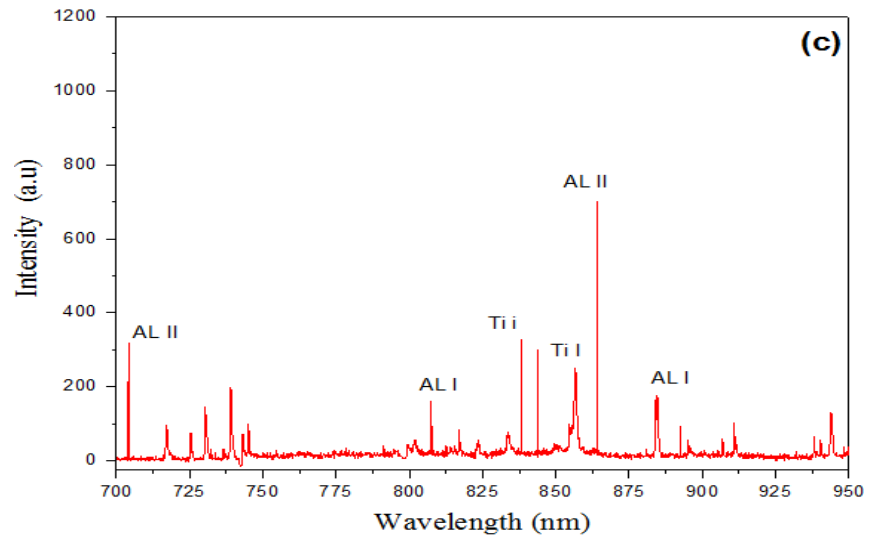

Fig. 1. Typical LIBS spectra recorded during analysis of Ti6Al4V sample1 at different spectral ranges (a) 230-330, (b) 400-650, and (c) 700-950nm.

TABLE I: SPECTROMETRIC PARAMETER OF THE EMISSION LINES OF

\begin{tabular}{|c|c|c|c|}
\hline Element & wavelengths & $\mathrm{A}^{*} \mathrm{~g}\left(\mathrm{~s}^{-1}\right)$ & $\mathrm{Eu}(\mathrm{eV})$ \\
\hline Ti I & 294.82 & $6.50 \mathrm{E} 8$ & 4.225 \\
\hline Ti I & 316.85 & 4.17E8 & 4.062 \\
\hline Ti I & 319.99 & $1.00 \mathrm{E} 9$ & 3.921 \\
\hline Ti I & 395.82 & $3.42 \mathrm{E} 8$ & 3.179 \\
\hline Ti I & 398.17 & $2.12 \mathrm{E} 8$ & 3.112 \\
\hline Ti I & 453.32 & $9.71 \mathrm{E} 8$ & 3.582 \\
\hline Ti I & 498.17 & $8.58 \mathrm{E} 8$ & 3.336 \\
\hline Ti I & 838.25 & 2.43E6 & 2.922 \\
\hline Ti II & 252.65 & $3.25 \mathrm{E} 8$ & 5.058 \\
\hline Ti II & 253.12 & $2.23 \mathrm{E} 8$ & 5.031 \\
\hline Ti II & 307.29 & $3.42 \mathrm{E} 8$ & 4.033 \\
\hline Ti II & 307.52 & $5.36 \mathrm{E} 8$ & 4.033 \\
\hline Ti II & 308.80 & $1.20 \mathrm{E} 8$ & 4.032 \\
\hline Ti II & 316.25 & $2.79 \mathrm{E} 8$ & 4.054 \\
\hline Ti II & 319.08 & $1.13 \mathrm{E} 8$ & 4.968 \\
\hline Ti II & 322.23 & $2.46 \mathrm{E} 8$ & 3.847 \\
\hline Ti II & 332.29 & $4.78 \mathrm{E} 8$ & 3.880 \\
\hline Ti II & 334.17 & $1.34 \mathrm{E} 8$ & 4.282 \\
\hline Ti II & 375.92 & $7.55 \mathrm{E} 8$ & 3.904 \\
\hline Ti II & 376.92 & 7.2 E8 & 3.869 \\
\hline Al I & 257.50 & $2.16 \mathrm{E} 8$ & 4.827 \\
\hline Al I & 265.24 & $2.84 \mathrm{E} 7$ & 4.672 \\
\hline Al I & 266.03 & $5.68 \mathrm{E} 7$ & 4.672 \\
\hline Al I & 807.53 & $3.17 \mathrm{E} 6$ & 5.620 \\
\hline Al I & 309.27 & $4.37 \mathrm{E} 8$ & 4.021 \\
\hline Al I & 394.40 & $9.98 \mathrm{E} 7$ & 3.142 \\
\hline Al I & 396.15 & $1.90 \mathrm{E} 8$ & 3.142 \\
\hline Al II & 390.06 & $2.40 \mathrm{E} 6$ & 10.59 \\
\hline Al II & 466.31 & $1.70 \mathrm{E} 8$ & 13.25 \\
\hline Al II & 556.33 & $4.63 \mathrm{E} 8$ & 15.47 \\
\hline Al II & 864.07 & $9.00 \mathrm{E} 7$ & 13.25 \\
\hline V I & 240.67 & $9.40 \mathrm{E} 7$ & 5.190 \\
\hline V I & 241.26 & 8.64E7 & 5.177 \\
\hline V I & 250.33 & $4.40 \mathrm{E} 7$ & 4.954 \\
\hline V I & 254.59 & $7.20 \mathrm{E} 7$ & 4.868 \\
\hline V I & 265.62 & $2.00 \mathrm{E} 8$ & 4.706 \\
\hline
\end{tabular}
TI6AL4V SAMPLE. 


\begin{tabular}{llll} 
V I & 326.32 & $5.20 \mathrm{E} 7$ & 3.798 \\
V I & 336.55 & $1.59 \mathrm{E} 8$ & 4.866 \\
V I & 379.03 & $6.90 \mathrm{E} 7$ & 3.545 \\
V I & 389.01 & $5.10 \mathrm{E} 7$ & 3.226 \\
V I & 419.15 & $3.90 \mathrm{E} 6$ & 3.224 \\
V I & 455.36 & $5.40 \mathrm{E} 8$ & 5.511 \\
V I & 613.53 & $3.02 \mathrm{E} 8$ & 4.606 \\
V I & 653.14 & $1.20 \mathrm{E} 8$ & 6.783 \\
& & & \\
V II & 270.61 & $1.05 \mathrm{E} 9$ & 6.686 \\
V II & 280.95 & $1.80 \mathrm{E} 8$ & 6.670 \\
V II & 281.02 & $3.70 \mathrm{E} 8$ & 4.653 \\
V II & 287.80 & $2.32 \mathrm{E} 8$ & 4.577 \\
V II & 289.24 & $5.00 \mathrm{E} 7$ & 4.983 \\
V II & 292.03 & $2.88 \mathrm{E} 8$ & 4.911 \\
V II & 371.54 & $1.20 \mathrm{E} 8$ & 6.783 \\
& & & \\
Fe I & 324.82 & $1.34 \mathrm{E} 8$ & 6.265 \\
Fe I & 379.85 & $3.50 \mathrm{E} 7$ & 4.177 \\
Fe I & 387.85 & $1.85 \mathrm{E} 7$ & 3.203 \\
Fe I & 401.58 & $1.07 \mathrm{E} 8$ & 6.134 \\
Fe I & 404.58 & $7.76 \mathrm{E} 8$ & 4.548 \\
Fe I & 495.75 & $4.60 \mathrm{E} 8$ & 5.308 \\
Fe I & 526.95 & $1.14 \mathrm{E} 7$ & 3.211 \\
\hline
\end{tabular}

\section{Calibration free quantitative analysis}

Before applying CF-LIBS, three conditions should be fulfilled in the experiment [15]. Firstly, high enough power density to ensure stoichiometric ablation. Secondly, optically thin plasma to avoid self-absorption in the spectral lines and finally the plasma should verify local thermal equilibrium (LTE).

a) Stoichiometric ablation: this condition ensures that the plasma composition has the same composition as the target material. Chan and Russo [16] reported that the laser ablation is stoichiometric at power densities about $10^{9}$ $\mathrm{W} / \mathrm{cm}^{2}$. In this study, the power density is highly enough not only to generate plasma on the target but also to verify the requirements of stoichoimetric ablation.

b) Optically thin plasma: to verify this condition, the intensity ratio of two different spectral lines $\mathrm{I} / \mathrm{I}^{\prime}$ of $\mathrm{Ti}$ element for sample 1 should be nearly the same as the ratio of $\mathrm{W} / \mathrm{W}^{\prime}$ i..e :

$$
\frac{W}{W^{\prime}}=\frac{A_{i j} g_{i} \lambda^{\prime}}{A_{i j}^{\prime} g_{i}^{\prime} \lambda}
$$

Where $(\lambda)$ is selected wavelength, $\left(A_{i j}\right)$ is the transition probability and $\left(g_{i}\right)$ is statistical weight . In Table II, we conclude that the intensity ratio was in good agreement according to (3).

TABLE II: COMPARISON BETWEEN THE INTENSITY RATIO OF TWO LINES OF TI AND THE RATIO OF THEIR CORRESPONDING TRANSITION PROBABILITIES.

\begin{tabular}{lccccc}
\hline Elem. & $\begin{array}{c}\text { Wavelength } \\
(\mathrm{nm})\end{array}$ & $\begin{array}{c}\text { Upper Energy } \\
\text { Level }(\mathrm{eV})\end{array}$ & $\begin{array}{c}\text { Transition } \\
\text { probabilit } \\
\mathrm{y}\end{array}$ & $\begin{array}{c}\text { Intensit } \\
\text { y ratio }\end{array}$ & $\begin{array}{c}\text { Tran. } \\
\text { Prob. } \\
\text { ratio }\end{array}$ \\
\hline Ti I & 364.61 & 3.399 & $1.3 * 10^{7}$ & 0.47 & 0.48 \\
& 366.89 & 3.999 & $2.7 * 10^{7}$ & & \\
\hline \hline
\end{tabular}

c) Local thermal equilibrium: for LTE requirements [15], the results of measuring electron density $\mathrm{Ne}$ of the plasma have to equal or higher than the lower limit of electron density determined according to the product of plasma temperature $T_{e}(K)$ and the energy difference between two energy levels $\Delta \mathrm{E}(\mathrm{eV})$ in McWhirter formula given by:

$$
N_{e}\left(\mathrm{~cm}^{-3}\right) \geq 1.6 * 10^{12} * \sqrt{T} *(\Delta E)^{3}
$$

Under these conditions, the population of excited level is related to the intensity of LIBS signal through Boltzmann equation:

$$
I_{\lambda}^{i j}=F C_{S} \frac{A_{i j} g_{i}}{U(T)} e^{-\frac{E_{k}}{k_{B} T}}
$$

$\mathrm{F}$ is an experimental parameter. $\mathrm{C}_{\mathrm{S}}$ is the concentration of a species, and $U(T)$ is partition function.

$\mathrm{T}_{\mathrm{e}}$ is evaluated using Boltzmann plot of $\ln \left(\mathrm{I} / \mathrm{A}_{\mathrm{ij}} \mathrm{g}_{\mathrm{j}}\right)$ against $E_{j}$ having slope of $\left(-1 / k_{B} T\right)$. As shown in Fig. 2, Boltzmann plot was drawn for Ti I, Ti II, Al I, V I, V II, and Fe I in sample1. Parallel Boltzmann plot for the multi elements in sample 1 proved the same value about $7439.08 \mathrm{~K}$ of $\mathrm{T}_{\mathrm{e}}$ for all elements presented in that as tabulated in Table III.

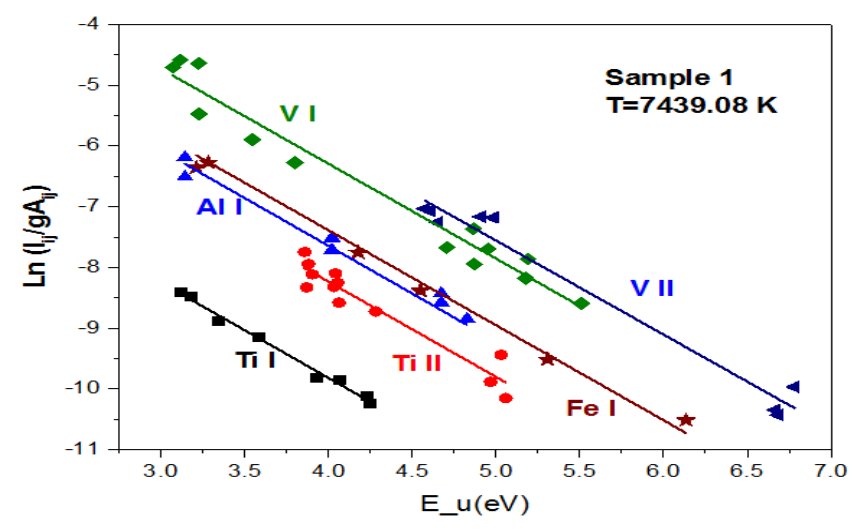

Fig. 2. A group of Boltzmann plots determined from the emission line intensities of Ti I, Ti II, Al II, V I, V II and Fe I presented in sample 1. The temperature was found to be $7439.08 \mathrm{~K}$.

Experimental $\mathrm{N}_{\mathrm{e}}$ is calculated by Stark-broadened line [17] through the following equation:

$$
N_{e}=2 W\left(\frac{\Delta \lambda_{F W H M}}{10^{16}}\right)
$$

where $\Delta \lambda_{F W H M}$ is half maximum of spectral line of the Lorentzian plot and $\mathrm{w}$ is the electron impact parameter. As shown in Fig. 3, the electron density of sample 1 was calculated for Ti II $(375.929 \mathrm{~nm})$ line with $\mathrm{W}=0.116 \mathrm{~nm}$ [18], $\Delta \lambda=0.1388 \mathrm{~nm}$ accordingly $\mathrm{N}_{\mathrm{e}}$ found to be $5.9 * 10^{16}$ $\mathrm{cm}^{-3}$. The lower limit of the $\mathrm{N}_{\mathrm{e}}$ calculated by (4) was $4.6 * 10^{13} \mathrm{~cm}^{-1}$ at (Ti I $375.92 \mathrm{~nm}$ ) and it is less than that measured experimentally using (6), which proves that the plasma is in LTE.

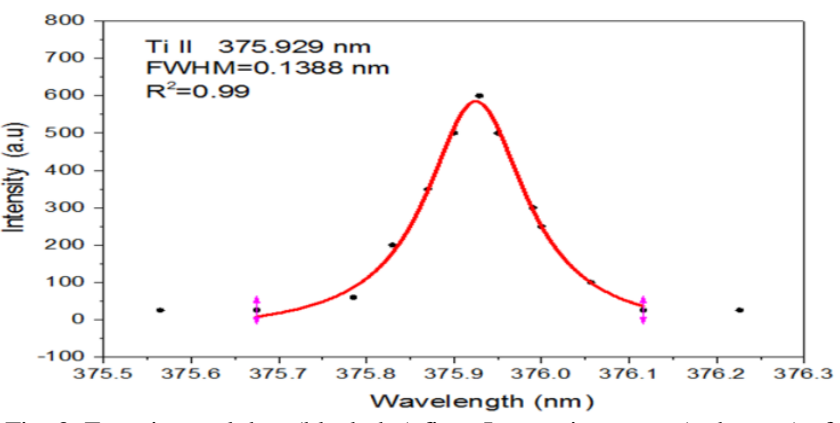

Fig. 3. Experimental data (black dot) fits a Lorentzian curve (red curve) of Ti II spectral line $375.929 \mathrm{~nm}$. The full width half maximum $\left(\Delta \lambda_{F W H M}\right)$ of $0.138 \mathrm{~nm}$ used to calculate the electron density $N_{e}$ 
Under this assumption, the electron density for each element can be derived from intensity ratio of two lines for two different ionization states of the same element using Saha equation [19]:

$$
N_{e}=6.04 * 10^{24}(T)^{3 / 2}\left(\frac{I \lambda}{g A}\right)_{i o n}\left(\frac{g A}{I \lambda}\right)_{\text {atom }} \times \exp \left[-\frac{\left(V^{+}+E_{\text {ion }}-E_{\text {atom }}\right)}{K_{B} T}\right](7)
$$

The transitions and corresponding $\mathrm{N}_{\mathrm{e}}$ calculated from (7) beside their spectroscopic parameters are shown in Table III.

TABLE III: MEASURED VALUES OF Plasma TEMPERATURE AND ELECTRON DENSITY ACCORDING TO FOUR EXAMINED TI ALLOYS

\begin{tabular}{|c|c|c|c|c|c|c|c|}
\hline \multicolumn{2}{|c|}{ Sample } & $\begin{array}{l}\mathrm{W}_{-\mathrm{i}} \\
(\mathrm{nm})\end{array}$ & $\begin{array}{c}\mathrm{W}_{-\mathrm{a}} \\
(\mathrm{nm})\end{array}$ & $\begin{array}{c}\mathrm{E}_{-\mathrm{i}} \\
(\mathrm{eV})\end{array}$ & $\begin{array}{c}E_{-\mathrm{a}} \\
(\mathrm{eV})\end{array}$ & $\begin{array}{c}\mathrm{T}_{\mathrm{e}} \\
(\mathrm{K})\end{array}$ & $\begin{array}{c}\mathrm{N}_{\mathrm{e}} * 10^{16} \\
\left(\mathrm{~cm}^{-3}\right)\end{array}$ \\
\hline \multirow{4}{*}{1} & $\mathrm{Ti}$ & 375.92 & 498.17 & 3.904 & 3.336 & \multirow{4}{*}{7439.1} & 2.18 \\
\hline & $\mathrm{Al}$ & 281.61 & 807.535 & 11.82 & 5.622 & & 0.09 \\
\hline & V & 371.54 & 623.07 & 4.911 & 2.256 & & 2.0 \\
\hline & $\mathrm{Fe}$ & 458.82 & 495.75 & 4.8 & 5.3 & & 4.12 \\
\hline \multirow{4}{*}{2} & $\mathrm{Ti}$ & 375.92 & 498.17 & 3.904 & 3.336 & \multirow{4}{*}{7253.1} & 2.0 \\
\hline & $\mathrm{Al}$ & 281.618 & 807.535 & 11.82 & 5.622 & & 0.087 \\
\hline & V & 371.54 & 623.07 & 4.911 & 2.256 & & 1.5 \\
\hline & $\mathrm{Fe}$ & 458.82 & 495.75 & 4.8 & 5.3 & & 3.43 \\
\hline \multirow{4}{*}{3} & $\mathrm{Ti}$ & 375.92 & 498.17 & 3.904 & 3.336 & \multirow{4}{*}{7076.2} & 0.9 \\
\hline & $\mathrm{Al}$ & 281.61 & 807.535 & 11.82 & 5.622 & & 0.052 \\
\hline & $\mathrm{V}$ & 371.54 & 623.07 & 4.911 & 2.256 & & 0.7 \\
\hline & $\mathrm{Fe}$ & 458.82 & 495.75 & 4.8 & 5.3 & & 3.12 \\
\hline \multirow{4}{*}{4} & $\mathrm{Ti}$ & 375.92 & 498.17 & 3.904 & 3.336 & \multirow{4}{*}{6826.4} & 0.7 \\
\hline & $\mathrm{Al}$ & 281.61 & 807.535 & 11.82 & 5.622 & & 0.02 \\
\hline & $\mathrm{V}$ & 371.54 & 623.07 & 4.911 & 2.256 & & 0.27 \\
\hline & $\mathrm{Fe}$ & 458.82 & 495.75 & 4.8 & 5.3 & & 3.33 \\
\hline
\end{tabular}

\section{Concentration of the elements present in each sample}

The concentration of the species $\mathrm{C}_{\mathrm{s}}$ is measured from the intercepts of the fitted lines in the Boltzmann plot Fig. 2; each intercept $q^{s}$ is a function of the number density $\left(\mathrm{n}_{\mathrm{s}}\right)$ of the individual species (s) in the plasma. The concentrations of any element could be determined from the emission of one neutral line according to:

$$
C^{S}=\frac{1}{F} U^{S}(T) e^{q^{S}}
$$

The concentration of a specific element of interest is given by the sum of the concentrations of neutral and singly ionized species [20]. Once $N^{I}$ of one species of a given element could be known. The concentration of the other ionization states $N^{I I}$ can be calculated by rearrangement of Saha- Boltzmann, which can be written as:

$$
\frac{N_{e} N^{I I}}{N^{I}}=\frac{2 U^{I I}(T)}{U^{I}(T)} \frac{2 \pi m_{e} k_{B}}{h^{3}} e^{-\frac{E_{i o n}}{k_{B} T}}
$$

$N^{I}, N^{I I}$ are the number densities for neutral atoms and singly ionized atoms, their summation $N^{I}+N^{I I}$ gives the total concentration of element presented in plasma.

After obtaining all necessary data, an extensive calculation was performed using Origin program. The inputs were the values of the slope, intercepts and the list of transition probabilities and degeneracy belong to each element. The concentrations of all different elements (Ti, Al, $\mathrm{V}$ and $\mathrm{Fe}$ ) presented in four examined samples using $\mathrm{CF}$ LIBS are summarized in Table IV. For comparison, a compositional analysis is also performed by using XRF analysis; the relative errors $\boldsymbol{e}_{\boldsymbol{r}}$ and city block distance (dist) between concentration vectors calculated from (10) and (11) respectively [21] are tabulated in Table IV.

$$
\begin{aligned}
& e_{r}=\frac{\left|\mathrm{C}_{\text {CFLIBS }}-\mathrm{C}_{\text {certified }}\right|}{\mathrm{C}_{\text {ertified }}} \\
& \text { dist }=\sum_{1}^{n} a b s|C-M| \mathrm{C}_{\text {CFLIBS }}
\end{aligned}
$$

TABLE IV: CONCENTRATION OF TI, AL AND V IN FOUR DIFFERENT SAMPLES.

\begin{tabular}{ccclll}
\hline \hline \multirow{2}{*}{ Sample } & $\begin{array}{l}\text { Conc. \% } \\
\text { LIBS }\end{array}$ & $\begin{array}{l}\text { Conc. \% } \\
\text { XRF }\end{array}$ & Error \% & dist. \\
\hline & $\mathrm{Ti}$ & 89.98 & 90.1 & 0.13 & \\
1 & $\mathrm{Al}$ & 5.8 & 6 & 3.3 & 0.64 \\
& $\mathrm{~V}$ & 4.0 & 3.7 & 8.1 & \\
& $\mathrm{Fe}$ & 0.22 & 0.2 & 10 & \\
\hline & $\mathrm{Ti}$ & 89.7 & 89.32 & 0.42 & \\
2 & $\mathrm{Al}$ & 6.03 & 6.2 & 2.7 & \multirow{2}{*}{1.06} \\
& $\mathrm{~V}$ & 4.0 & 4.2 & 4.7 & \\
& $\mathrm{Fe}$ & 0.27 & 0.28 & 3.5 & \\
\hline & $\mathrm{Ti}$ & 90.13 & 91.78 & 0.71 & \\
3 & $\mathrm{Al}$ & 5.65 & 5.2 & 8.6 & 1.39 \\
& $\mathrm{~V}$ & 3.87 & 3.7 & 4.5 & \\
& $\mathrm{Fe}$ & 0.35 & 0.32 & 9.3 & \\
\hline & $\mathrm{Ti}$ & 90.1 & 89.8 & 0.33 & \\
4 & $\mathrm{Al}$ & 5.63 & 5.8 & 2.93 & 0.6 \\
& $\mathrm{~V}$ & 4.09 & 4.2 & 2.6 & \\
& $\mathrm{Fe}$ & 0.18 & 0.2 & 10 & \\
\hline
\end{tabular}

The calculated average relative errors of $\mathrm{Ti}, \mathrm{Al}, \mathrm{V}$ and $\mathrm{Fe}$ were $0.39 \%, 4.38 \%, 4.94 \%$ and $8.2 \%$, respectively. These relatively small measurement error values especially for minor elements $\mathrm{Fe}$ indicate the capability of CF LIBS for curate quantitative analysis with quite accepted results.

\section{E. Hardness analysis}

Considering industrial application of LIBS, the relation between material compressive strength and LIBS analysis has been investigated. Herein, the intensity ratio of the ionic to atomic spectral emission lines of $\mathrm{Ti}$ are examined in view of the expected correlation between the extent of ionization and the hardness of the Ti alloys. The recorded LIBS spectra of four samples of $\mathrm{Ti}$ alloys with different hardness are shown in Fig. 5.

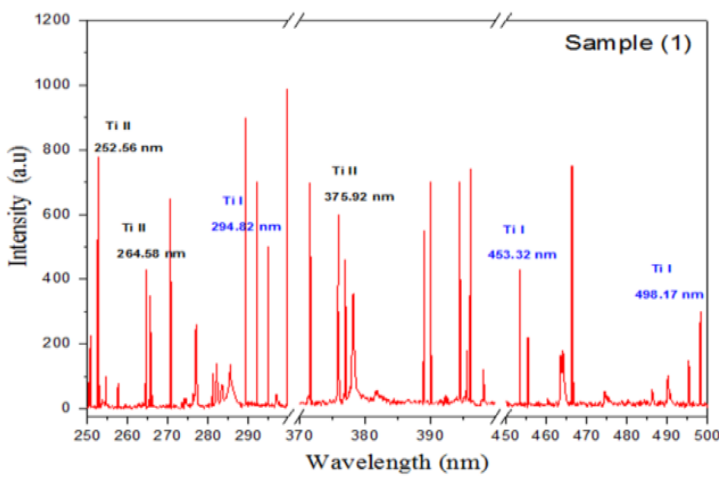



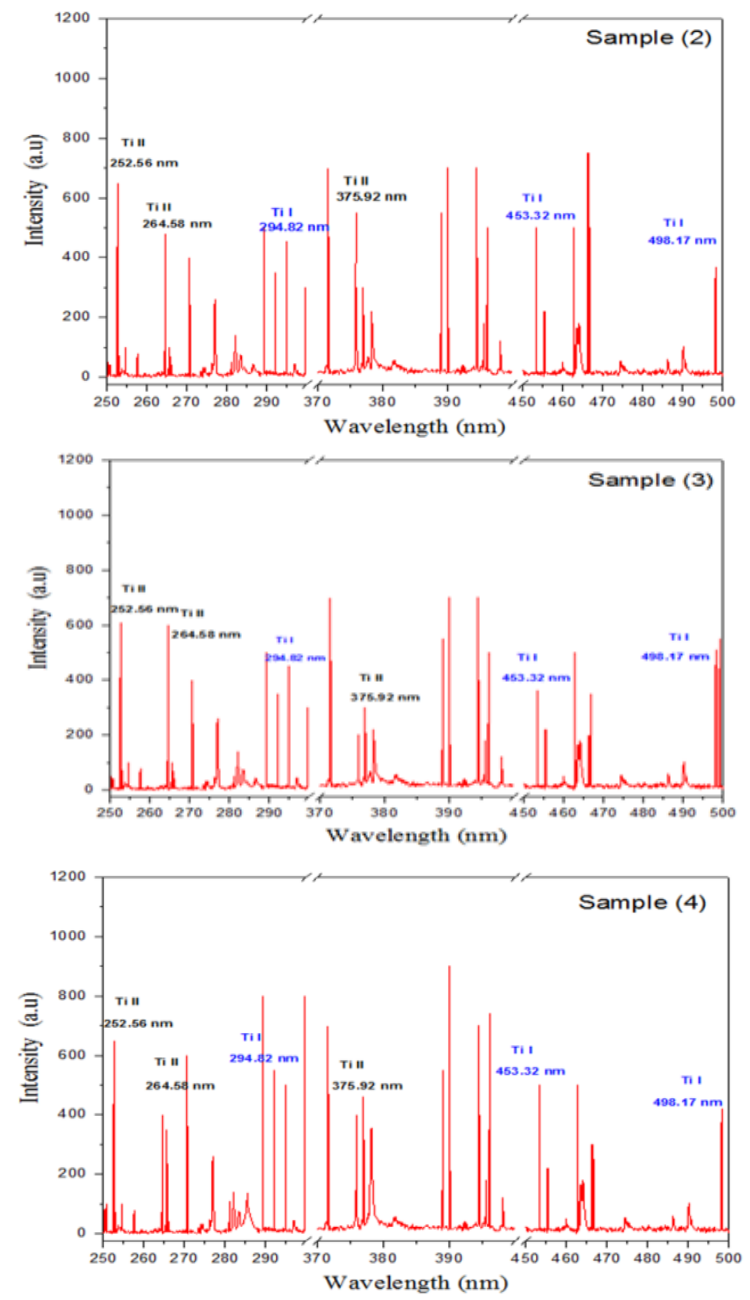

Fig. 5. Ionic and neutral emission lines of Ti for four samples captured during analysis of surface hardness.

The experimental ratios of intensities $\mathrm{I}_{\lambda}(\mathrm{Ti} \mathrm{II}) / \mathrm{I}_{\lambda}(\mathrm{Ti} \mathrm{I})$ have been measured and plotted versus Vickers hardness for each sample as shown in Fig. 6. Each line represents the variation of the ratio as a function of sample hardness exhibits a linear behavior that may be attributed to stronger repulsive force of laser induced shock waves obtained at harder surfaces. According to the value of linear regression value $\mathrm{R}^{2}$, the ratio at (Ti II $252.56 \mathrm{~nm}$ )/(Ti I 294.82nm) was 0.95 which indicates the best linear relation for surface hardness estimation.

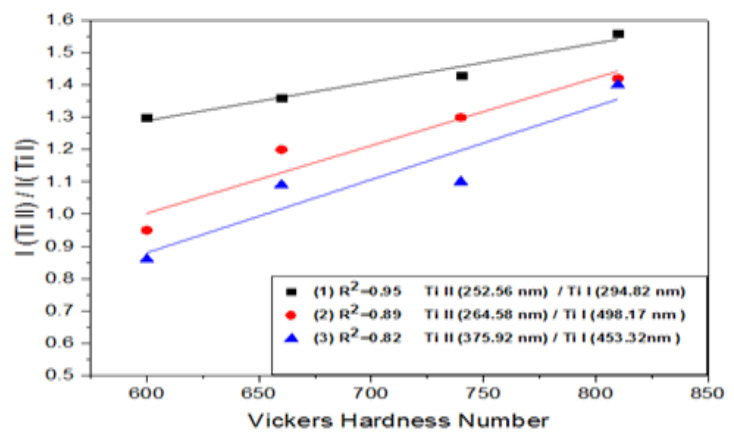

Fig. 6. The intensity ratio of $\mathrm{Ti}$ II/Ti I as a function of Vickers hardness number of different Ti 6Al4V samples.

On the other hand, since the plasma shockwave velocity may affect the temperature of the laser induced plasmas, this temperature could be used as an indicator of sample hardness, Vickers surface hardness values of four Ti $6 \mathrm{Al} 4 \mathrm{~V}$ samples against plasma excitation temperature are plotted in Fig. 7. The straight line represents a linear fit to the data; it can be clearly seen that $T_{e}$ has a linear relationship with increasing surface hardness as expected. These results are in good agreement with those obtained other related studies [11], [22] in the case of solid materials like concrete and bio-ceramics respectively.

These results evidenced that the LIBS analysis based on $\mathrm{CF}$ method was capable to monitor the composition and the hardness of solid targets. More importantly, CF-LIBS gives an advantage of carrying out direct, rapid and online simultaneous elemental composition analysis and hardness estimation using a single instrument.

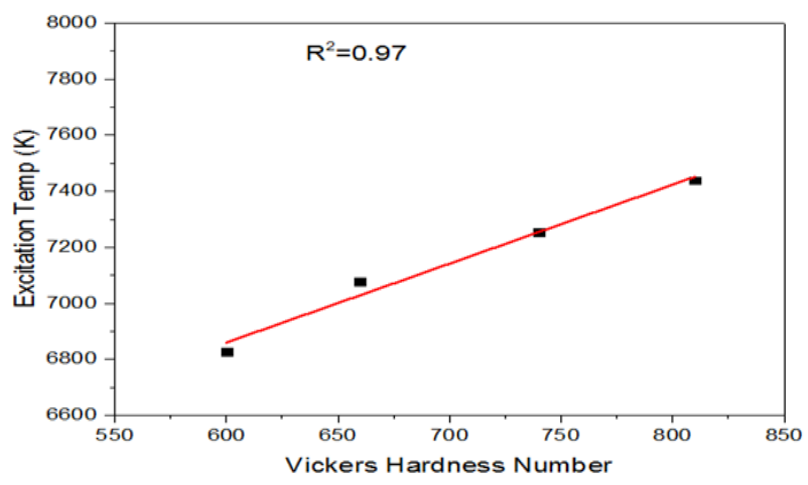

Fig. 7. Plasma excitation temperature versus Vickers hardness measurements for examined Ti alloys.

\section{CONCLUSION}

In this work, CF-LIBS procedure is used to analyze Ti6Al4V samples. The plasma temperature and electron density was calculated using the Saha-Boltzmann plot and Stark broadening, these values have been found to be respectively. The concentration of $\mathrm{Ti}, \mathrm{Al}$, and $\mathrm{V}$ are determined and were in good agreement with nominal concentrations measured by XRF which indicate the analytical capability of CF-LIBS. A specific procedure using ratio between the intensities of ionized and neutral Titanium emission lines was developed in order to estimate the correlation between this ratio and the surface hardness of examined samples. The results also revealed a linear dependence between excitation plasma temperature and sample hardness.

\section{REFERENCES}

[1] R. R. Boyer, An overview on the use of titanium in the aerospace industry," Materials Science and Engineering: A, vol. 213, no. 1-2, pp. 103-114, Aug. 1996.

[2] F. S. Froes and M. A. Imam, "Cost Affordable Developments in Titanium Technology and Applications," Key Engineering Materials, vol. 436, no.5, pp. 1-11, May 2010.

[3] C. Leyens and M. Peters, Titanium and titanium alloys: fundamentals and applications. Wiley-VCH, 2003.

[4] D. W. Hahn and N. Omenetto, "Laser-induced breakdown spectroscopy (LIBS), part II: review of instrumental and methodological approaches to material analysis and applications to different fields. Appl. Spectrosc, Vol. 66, pp. 347-419, 2012

[5] D. A. Cremers and L. J. Radziemski, Handbook of Laser-induced Breakdown Spectroscopy. $2^{\text {nd }}$ ed. JohnWiley \& Sons, 2013.

[6] A. Ciucci, M. Corsi, V. Palleschi, S. Rastelli, A. Salvetti, E. Tognoni, "New procedure for quantitative elemental analysis by laser-induced plasma spectroscopy," Appl. Spectrosc, Vol. 53 pp. 960-964,1999.

[7] M.V. Belkov, V.S. Burakov, V.V. Kiris, N.M. Kozhukh, S.N. Raikov, "Spectral standard-free laser microananlysis of gold alloys," J. Appl. Spectrosc, Vol. 72, pp. 376-381, 2005. 
[8] G. S. Senesi, "Laser Induced Breakdown Sepctroscopy (LIBS) Applied to Terrestrial and Extraterrestrial Analogue Geomaterials with Emphasis to Minerals and Rocks," Earth-science Reviews, Vol. 139, pp. 231-267, 2014.

[9] J. D. Pedarnig, P. Kolmhofer, N. Huber, B. Praher. Heitz J., R. Rössler, "Element analysis of complex materials by calibration-free laser-induced breakdown spectroscopy," Appl. Phys. A, Vol. 112, No. 1, pp. 105-111. 2013.

[10] K. K. Herrera, E. Tognoni, N. Omenetto, B. W. Smith, J. D Winefordner, "Semi-quantitative analysis of metal alloys, brass and soil samples by calibration-free laser-induced breakdown spectroscopy: recent results and considerations," J. Anal. At. Spectrom, Vol. 24, pp. 413-425, 2009.

[11] K. Tsuyuki, S. Miura, N. Idris, K. Hendrik, T.Jie, K.Kagawa, "Measurements of concrete strength using the emission intensity ratio between Ca II $396.8 \mathrm{~nm}$ and Ca I $422.6 \mathrm{~nm}$ in a NdYAG laser induced plasma,"Appl. Spectrosc, Vol. 60, pp. 61-64, 2006.

[12] Z. Abdel-Salam, Z. Nanjing, D. Anglos, M.A. Harith, "Effect of experimental conditions on surface hardness measurements of calcified tissues via LIBS," Appl. Phys. B Vol. 94, pp. 141-147, 2009.

[13] C. Phipps, and M. Michaelis, "LISP: Laser Impulse Space Propulsion," Laser and Particle Beams, Vol. 12, No. 1, pp. 23-54, 1994.

[14] Available: http://physics.nist.gov/PhysRefData/ASD/lines_form.html

[15] S. Pandhija, N. Rai, A. Rai, S. Thakur, "Contaminant concentration in environmental samples using LIBS and CF-LIBS," Applied Physics B , Vol. 98, pp. 231-241, 2010.

[16] W. T. Chan, R. E. Russo, "Study of laser-material interaction using inductively coupled plasma -atomic emission spectrometry,"Spectrochim. Acta, Part B: Atom. Spectrosc. Vol. 46 pp. 1471-1486, 1991.

[17] C. Colon, G. Hatem, E. Verdugo, P. Ruiz, J. Campos, "Measurement of the Stark-Broadening and Shift Parameters for Several Ultraviolet Lines of Singly Ionized Aluminum," J. Appl. Phys. Vol. 73, No. 10, pp. 4752-4758, 1993.

[18] J. Manrique J. A. Aguilera and C. Arag, "Experimental Stark widths and shifts of Ti II spectral lines," MNRAS, Vol. 462, pp. 1501-1507, 2016.

[19] H. Shakeel, S. U. Haq, , G. Aisha, and A. Nadeem, "Quantitative analysis of Al-Si alloy using calibration free laser induced breakdown spectroscopy (CF-LIBS)," Physics of Plasmas Vol. 24, No. 063516, 2017.
[20] M. Hornackova, J. Plavcan, J. Rakovsky, V. Porubcan, D. Ozdin, et al., "Calibration-Free Laser Induced Breakdown Spectroscopy as an Alternative Method for Found Meteorite Fragments Analysis," Eur. Phys. J.: Appl. Phys. Vol. 66, No. 1, 2014.

[21] E. Tognoni, G. Cristoforetti, S. Legnaioli, V. Palleschi, "CalibrationFree Laser-Induced Breakdown Spectroscopy: State of the art," Spectrochimica Acta Part B Vol. 65, pp. 1-14, 2010.

[22] J.S. Cowpe, R.D. Moorehead, D. Moser, J.S. Astin, S. Karthikeyan, S.H. Kilcoyne, G. Crofts, R.D. Pilkington, "Hardness determination of bio-ceramics using Laser-Induced Breakdown Spectroscopy,' Spectrochimica Acta Part B Vol. 66, pp. 290-294, 2011.

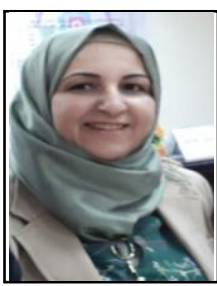

Tagreed K. Hamad was born in Baghdad, Iraq on 8th September, 1972. She holds a Bachelor of Sciences in Physics in 1993 from University of Baghdad, Baghdad- Iraq Master of Applied Sciences (Laser Physics) in 1997 from University of Technology, Baghdad- Iraq and $\mathrm{PhD}$ in Physics in 2018 from AlNahrain University, Baghdad- Iraq.

She is currently a Lecturer in the Department of Physics Al-Nahrain University, Baghdad- Iraq. She has published more than Fifteen scholarly articles and participated in several workshops, seminars and conferences. Her research interests have been in laser application, laser material interaction, industrial application of laser, linear and nonlinear optical properties.

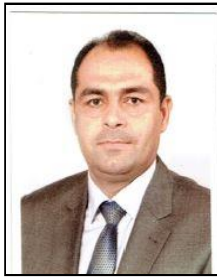

Hussein T. Salloom was born in Baghdad, Iraq on 28th March, 1972. He holds a Bachelor of Applied Physics in 1994 and Master of Laser Physics in 1997 from University of Technology and PhD in Physics (Photonics) in 2014 from Al-Nahrain University, Baghdad- Iraq.

He is currently a Lecturer and Scientific Lecturer in Al-Nahrain Nanorenewable energy research center, Baghdad. He has published more than twenty scientific articles and participated in several national and international workshops and conferences. Her research interests have been in renewable energy resources, nanomaterial synthesis, photonic crystal fiber sensors and laser application. He is a member European Optical Society (EOS) and Italian Society of Optics and Photonics ( SIOF). 